\title{
Labyrinthe
}

$6 \mid 2000$

Numéro 6

\section{Le barreau au service d'une ambition politique : maître Jean Zay à Orléans dans les années trente}

Pierre-Olivier Aguinalin

\section{(2) OpenEdition \\ 12 Journals}

Édition électronique

URL : http://journals.openedition.org/labyrinthe/404

DOI : $10.4000 /$ labyrinthe.404

ISSN : 1950-6031

Éditeur

Hermann

Édition imprimée

Date de publication : 1 juin 2000

Pagination : 124-125

Référence électronique

Pierre-Olivier Aguinalin, « Le barreau au service d'une ambition politique : maître Jean Zay à Orléans dans les années trente », Labyrinthe [En ligne], 6| 2000, mis en ligne le 20 mars 2005, consulté le 06 mai 2019. URL : http://journals.openedition.org/labyrinthe/404 ; DOI : 10.4000/labyrinthe.404

Ce document a été généré automatiquement le 6 mai 2019.

Propriété intellectuelle 


\title{
Le barreau au service d'une ambition politique : maître Jean Zay à Orléans dans les années trente
}

\author{
Pierre-Olivier Aguinalin
}

\begin{abstract}
Cet aperçu de recherche est tiré d'une maîtrise d'histoire contemporaine soutenue à l'université de Paris I Panthéon-Sorbonne, sous la direction d'Antoine Prost. Le mémoire est consultable au Centre de Recherche d'Histoire des Mouvements Sociaux et du Syndicalisme (Paris I), aux archives départementales du Loiret à Orléans et à la médiathèque d'Orléans.
\end{abstract}

1 Jean Zay naît le 6 août 1904 à Orléans. Son entrée précoce en politique est marquée par son succès du 8 mai 1932, lorsqu'il est élu, à vingt-huit ans, député radical du Loiret. Son autorité au sein du Parti radical le conduit par la suite à exercer de hautes fonctions ministérielles : il est notamment le plus jeune ministre de la $\mathrm{III}^{\mathrm{e}}$ République, en l'occurrence ministre de l'Éducation Nationale et des Beaux-Arts du 4 juin 1936 au 3 septembre $1939^{1}$.

2 L'étude de cette carrière politique brillante et rapide imposait de s'intéresser aux origines de cette vocation, donc à la formation de l'homme politique. L'étude a alors consisté à examiner les circonstances et les conditions qui ont favorisé, dans le contexte professionnel de sa carrière d'avocat, cette ascension politique : en effet, Jean Zay fut d'abord un avocat brillant aux talents oratoires reconnus. L'intérêt de cette étude était donc de répondre à la question : comment un avocat, sous la $\mathrm{III}^{\mathrm{e}}$ République, entre-t-il en politique?

3 À partir des comptes rendus de procès dans la presse locale et des archives privées de Jean Zay - soit 231 dossiers d'affaires de l'avocat entre 1928 et 1936, contenant ses notes, le fichier de sa clientèle, ses honoraires, sa correspondance avec ses clients, et surtout ses plans de plaidoirie, source rare qui permet d'étudier les méthodes de construction d'une 
plaidoirie et les techniques de l'art oratoire -, il nous a été donné de voir agir quotidiennement l'avocat au barreau d'Orléans à cette époque, de voir les types d'affaires qu'il a pu défendre et d'établir une sociologie de sa clientèle, étude riche d'enseignements lorsque l'on s'intéresse à la construction d'une carrière politique. Une relation forte avec le tribunal, une défense de son client bien menée et un art oratoire parfaitement maitrisé nous autorisent à reconnaître en Jean Zay un avocat de grande valeur. Il est certain que c'est lors des procès d'assises que Jean Zay a donné la mesure de son talent ; en effet, il a su insuffler une atmosphère théâtrale à ces procès, grâce à son éloquence que la force de l'ironie, de l'indignation, de l'indulgence et du pathétique rendait incomparable. L'avocat Zay s'y révèle sous les traits du juriste, de l'enquêteur, du confesseur, de l'historien, du moraliste et de l'acteur, car il n'est pas d'aspects de la vie intellectuelle, sociale et morale qui lui aient été étrangers. Ce sont surtout ces victoires aux assises qui lui valent popularité et reconnaissance populaire, deux atouts-clefs pour celui qui nourrit des ambitions politiques ${ }^{2}$.

4 Cependant, Jean Zay ne s'est pas limité aux seuls combats du prétoire, il a cherché à s'imposer comme un acteur à part entière de la vie de la cité. Il a alors su mettre sa carrière professionnelle au service de son ambition politique. Il connaissait en effet la place éminente occupée par les membres du barreau dans les circuits relationnels et d'influence qu'étaient, dans les années trente, les syndicats professionnels. Jean Zay noue ainsi des relations fortes, en sa qualité de conseil juridique à la Fédération Artisanale du Loiret. Ce rôle se double de celui de " guide ", puisqu'il informe les artisans, les éclaire (grâce à ses compétences juridiques) dans leur vie sociale au mieux de leurs intérêts matériels et moraux. En même temps, il rejoint son idéal d'homme politique et sa volonté de « lutter contre les oligarchies financières, les banques et de faire de l'État un État économique où les professions et les syndicats joueraient un rôle considérable ". L'avocat-conseil revêt remarquablement les habits de l'homme politique auprès du Comité d'action des artisans qui, dans sa structure, ses enjeux, ses intérêts et sa propagande, se définit comme un acteur collectif parmi d'autres de la vie politique. Jean Zay y fait ainsi son apprentissage politique, et saura gagner le soutien électoral des artisans lors de sa candidature en 1932. On voit bien là comment son rôle de conseiller privilégié d'un groupe socio-professionnel a conforté indéniablement la position sociale de Jean Zay et sa double image d'« expert connaissant bien les dossiers » et de militant.

5 Le parcours professionnel de Jean Zay est donc un parcours politique, qui le prépare à la vie, aux débats et aux enjeux politiques. Cependant, ce parcours n'est pas unique sous la III ${ }^{e}$ République, puisque celle-ci, en établissant le suffrage universel masculin, a offert à ceux qui détenaient le secret de l'éloquence de nouvelles chances de promotion sociale. De Gambetta à Poincaré, ce fut la "République des avocats ", nouvelle élite qui ne devait son statut social et sa promotion politique qu'à ses qualités intellectuelles et oratoires. 


\section{NOTES}

1. Voir la biographie de Jean Zay par Marcel Ruby, La Vie et l'œuvre de Jean Zay, Paris, M. Ruby, 1969, 509 p.

2. Cf. Catherine Fillon, La Profession d'avocat et son image dans l'entre-deux-guerres, thèse de l'université Lyon III, 1995, 600 p. 